http://jmscr.igmpublication.org/home/ ISSN (e)-2347-176x ISSN (p) 2455-0450 crossref DOI: https://dx.doi.org/10.18535/jmscr/v8i4.93

\title{
Coping with Health and Psychosocial Well-being of Older Cohorts: Impact of Medical Social Workers in Nigeria
}

\author{
Authors \\ Jecinta Chibuzor. Ene (Ph.D Candidate) ${ }^{1^{*}}$, Dr Yemi Adewoyin ${ }^{2}$ \\ Ijeoma Blessing. Uche (Ph.D Candidate) ${ }^{3}$ \\ ${ }^{1,3}$ Department of Social Work \\ ${ }^{2}$ Department of Geography \\ Faculty of the Social Sciences, University of Nigeria, Nsukka \\ *Corresponding Author \\ Jecinta Chibuzor. Ene (Ph.D Candidate)
}

\begin{abstract}
Health is one issue that cannot be compromised. With changing demographics in aging, older cohorts experience decline in health and psychosocial well-being. It then follows that the next line of action is caregiving. This study examined the perceived challenges and coping strategies with health and psychosocial well-being of older cohorts and social work intervention for them and their caregivers. Results were presented from a qualitative analysis using Focus Group Discussion (FGD). Fifty-six (56) participants from four purposively selected rural communities in Enugu-West Senatorial zone (forty (40) caregivers and sixteen (16) older adults) were enlisted in the study. Result indicated that older cohorts in Nigeria face tremendous challenges in coping with health and psychosocial well-being particularly in three major areas including, changes in family structure, absence of social support and health service utilization. The study recommends the implementation of government policy particularly in health and social service sectors; recruitment of skill based medical social workers with other health personnel to coordinate coping strategies including skill acquisition, intervention, follow up treatment, counseling and inculcating health education programs to older cohorts and their caregivers.
\end{abstract}

Keywords: caregivers; health; older cohorts; psychosocial; social workers and well-being.

\section{Introduction}

Health is one issue that cannot be compromised. As people age, they encounter different health experiences including limited regenerative abilities and are more prone to diseases, sickness and syndromes than younger adults (National Ageing Research Institution (NARI), 2014). With changing body composition associated with ageing; older cohorts become functionally disabled and will require some form of assistance with personal care particularly in coping with health and psychosocial well-being (WHO, 2017). In most countries, the age 65 and older is used for older population (Oluwagbemiga, 2016). 
However, the United Nations agreed cut-off age is 60 years and above (Moody, 2010). This appears acceptable in the African setting including Nigeria; as the retirement age of majority of civil servants in the country is based on this age (Alwajud-adewusi, 2019).

Since the $21^{\text {st }}$ century, the ageing population has been growing rapidly with estimates of people aged 65 and above constituting $12 \%$ of global population in 2015 (US Census Bureau Statistic, 2016). This proportion though concentrated in developed countries (like United Kingdom and Germany); many developing countries (Nigeria inclusive) are in the era of an ageing population (United Nation Department of Economic and Social Affairs (UNDESA), 2012). To show the increase in ageing population of Nigeria, the Population Division (UNDESA, 2012) projected the population of Nigerians (60 years and above) from 8.8 million in 2012 to 28 million by 2050 . Adebowale (2016) reported that the proportion of this age group in the country is expected to go up to $22 \%$ by 2016 . Furthermore, the National Bureau of Statistics (2017) maintained that the country's older cohorts' population is increasing from 8,741,292 in 2013 to 9,622,056 in 2016 with expected increase in years to come.

As the ageing population increases globally and in Nigeria specifically, there is a clear indication of transformation in all aspects of the society ranging from changes in economic security, employment opportunity, family structure, housing resources, transportation services and particularly health service utilization among others (Animasahu \& Chapman, 2017). For instance, the country was ranked $187^{\text {th }}$ position among the 191 United Nations member states in health systems, by the World Health Organization with statistics of 33,303 general hospitals, 20,278 primary health care centers and 59 teaching hospitals and medical centers (WHO, 2010). Similarly, the provision of health care laws and programmes for older cohorts in the country has not received appropriate attention, with health expenditure of $3.7 \%$ Gross Development Product (GDP) as at 2014 (WHO,
2014). Additionally, the health care system has been with a dramatic increase in the number of older cohorts and limited specialized geriatric medical practitioners with the ratio of seven geriatrician to over 900,000 aged persons with chronic medical conditions including diabetes, cancer, arthritis and cardiovascular diseases among others (Alenoghena, Aigbirenolen, Abjegali \& Ejiemai, 2017; Usman, 2018). These evidences are clear indications that health care management for older cohorts particularly in a middle and low income country like Nigeria has not received adequate consideration (Abanyam, 2013; Dokpesi, 2017). The implication is that most older cohorts with health related conditions are at risk of psychosocial well-being, become frail, functionally disabled and may not adequately utilize health care services but may resort to the use of inadequate alternative medicine which they perceive to be cheaper and accessible (Ene, Adewoyin, Chukwu \& Patrison, 2018; Schnabel, Binting, Witt \& Teut, 2014).

Nevertheless, absence of social support system, changing demographics in Nigeria in addition to cultural consideration has presented several challenges that may influence the health and psychosocial well-being of older cohorts. The absence of social support service (including alternative care system, financial support, and health care policies among others) to a large extent increases their vulnerability; with total dependency on others (Okoye and Asa, 2011; Oluwagbemiga, 2014). Again, owing to economic situation in recent times, family members can no longer adequately provide their own needs, hence attending to the needs of their older cohorts seems difficult (Okoye, 2014; Abanyam, 2011). The traditional family structure which have been characterized with the recognition and appreciation of older cohorts is gradually eroding away undermining the roles, status and welfare of the aged, who are becoming socially isolated and thereby affects their psychological and social well-being through feeling of depression, loneliness, neglect and many more (Abanyam, 
2013; Akpunne, 2015). More so, the cultural familial sense of responsibility has been replaced by forces including migration of younger adults particularly from rural to urban areas (urbanization), quest for female education and job opportunities, social and political instability; has incapacitated older adults to no longer expect to be recipient of family care (Adeleke, Adebowale \& Oyinlola, 2017).

Against the backdrop, there are accounts of government effort in ensuring the well-being of older cohorts. The Nigerian government has revitalized the National Pension Commission (PENCOM) and the Pension Transitional Arrangement Directorate (PTAD) to ensure that older cohorts receive their entitlements faster than usual on retirement. Secondly, there has been approval for the establishment of the National Senior Citizen Center Act (NSCCA) 2018, with the purpose of ensuring community base and support services (Adebajo, 2019; Wrigon, 2018). In the health care system, the only available health care programme for older adults in the country is the National Health Insurance Scheme (NHIS). This insurance scheme only meant for Nigerian civil servants does not cover all older cohorts (Adinma, Brian \& Adinma, 2010). Unlike developed countries, developing countries like Nigeria specifically, have not intervened as they should particularly in proffering health care and social security policies for the aged; leaving them to constitute the poorest and most vulnerable group in the society (Abanyam, 2013).

Scholars have advocated that care-giving assistance to any of the vulnerable groups including older cohorts does not only entail the act of giving assistance with personal, social and physical activities of daily living; but encompasses effective intervention particularly in coping with health and psychosocial well-being (Ene, 2010; Friedemann \& Buckwalter, 2014; Litwin, Stoeckel \& Roll, 2014; Penning and Zeheng, 2016). Be that as it may, older cohorts and their caregivers report distressing interpersonal difficulties in this regard (Okoye \&
Asa, 2011). It is in this vein that caregivers should construct social skills and psychosocial adjustment as a coping strategy that help them deal with the changing demands and needs of others who are involved in their lives (Barham, Del Prette \& Queluz, 2018). To be effective, coping strategies may require problem solving skills including health and social skills like empathy, communication skills and ability to work co-operatively with others. For instance caregivers may need to find ways to encourage older cohorts to alter routines, adjust to their declining health through health service utilization and request additional assistance from family members particularly when care-giving demands increases.

Situating this study theoretically is Ajzen's (1985) theory of planned behaviour. This theory recognizes that behaviours such as coping with health and psychosocial well-being of older cohorts could be promoted by changing demographics, in addition to cultural consideration (care-giving) that has evolve into becoming norms. When cultural values no longer promote good health, they lead to behaviours that run into conflict with established health standards (Agbawodikeizu, Agwu, Okoye \& Igwe, 2019). Changing this orientation and trend therefore falls within the purview of medical social work professionals. Hence, it is imperative to scale up their presence and importance in the country.

Social workers are professionals who promote social change and development, social cohesion, empowerment and liberation of people (Okoye, Ebimgbo \& Ene, 2017). They aim at engaging people to address life challenges and enhance well-being (IASW, 2011). Social workers constitute an important part of health, psychological and social care by providing essential interventive roles to older cohorts, families and caregivers (Ayangunna \& Mojoyinola 2012). In Nigeria, the practice of social work profession in health care setting is not yet popular and encounters uncertain future particularly in rural communities (Okafor, Onalu, 
Ene \& Okoye, 2018). Like other health care professionals, medical social workers are being pushed to rethink their mission and identify their practice components and gaps needing their expertise including health education programme for older cohorts and caregivers on existing health and social skills, utilization of health care services, in-home medical assistance, follow up treatment upon discharge among other interventive roles (Ene, Nnama-Okechukwu, Uzuegbu, \& Okoye, 2018; Okafor et al, 2018; Okoye et al, 2017; Portraj, 2016). This implies that medical social workers in collaboration with other health workers should champion health management and psychosocial well-being in medical settings and homes within the communities to enable caregivers address specific health and psychosocial challenges.

Finally, several studies abound that deal extensively on health and psychological wellbeing of older cohorts in Nigeria (Adebowale, Atte, \& Ayeni, 2012; Animasahu \& Chapman, 2017; Akpunne, 2015; Adinma, Brian \& Adinma, 2010; Oluwagbemiga, 2014). This time, it is essential to determine the perceived challenges and coping strategies with health and psychosocial well-being of older cohorts in Nigeria from the social work perspective. It is hoped that findings from this study will impact broad knowledge on roles of medical social workers while providing the essences for co-opting their services to improve the health and psychosocial well-being of older cohorts, their family members and particularly caregivers.

\section{Participants/Method \\ Ethical Approval}

The study instrument and methodology was reviewed and approved by the General Hospital ethical committee, State Health Management Board, Nsukka Local Government Area, Enugu State, Nigeria.

\section{Study Area}

The study area is Enugu State. The state is one of the 36 states in the south-east geopolitical zone in
Nigeria with three senatorial districts including Enugu-West. From the seventeen (17) Local Government Areas (L.G.A) in the state, four rural autonomous communities (each from one L.G.A) were chosen using simple random sampling namely Abia in Udi, Ngbogho in Agwu, Oghe in Eziagu and Akpugo in Oji all in Enugu-West Senatorial district. These communities are homogenous in culture and language with Igbo as the dominant ethnic group.

\section{Participants and Recruitment}

A total of fifty-six (56) participants were selected using purposive cum availability sampling techniques. Study participants were categorized into two groups; namely caregivers and older cohorts study participants. This technique according to Correa-Torres, Conroy, RundleKahn, \& Ogilvie (2018) can also be useful when attempting to identify a small number with some characteristic and experience. The first group (FGD 01) comprised of forty (40) caregivers while the second group (FGD 02) comprised of sixteen (16) older cohorts. These participants reside within each of the four communities randomly selected for the study; such that ten (10) respondents made up of five men and women caregivers were selected from each community to get the required forty (40) participants. These caregivers were selected with the assistance of traditional, religious, men and women leaders in these communities. With the assistance of the selected caregivers, sixteen (16) older cohorts made up of two men and women; four from each community were also purposively selected for the focus group discussion (FGD). The rationale behind gender consideration is to give each gender equal opportunity to be represented. The criteria used to select the caregiver participants in these communities include; willingness to participate, availability on the day of discussion, residing and providing care (a caregiver) to older cohort(s) and within the age range of 20-50 years. While older cohort participants must have retired from civil service employment, available on the date of discussion, has a care provider (caregiver) and is 
aged 60 years and older as at the time of this study. The study location was selected based on the convenience of the participants. However, we used the open space in the community hall and the primary school vacant classroom.

\section{Study Procedures}

The study design is an explorative research design which relied on qualitative research method; using the Focus Group Discussion (FGD). The FGD sessions were conducted in Igbo and Pidgin English language based on the preference of the study participants. They were also done at their convenience. Given ethical implications, oral informed consent was obtained from the participant after informing them of the objective of the study. The study participants were also informed that they are free to withdraw at any point during the FGD. The discussions were recorded with our audio tape having obtained permission to record the conversation; in all five FGDs (three for caregivers and two for older adults) were held. Each session was made up of 814 participants with one session coming up on a weekly base. This lasted for five weeks (JanuaryFebruary, 2020). Two research assistant social workers moderated the sessions with the supervision of the team leader. A male researcher moderated the all male sessions while the female researcher moderated the all female sessions. The justification is to enable the participants to express their views freely (Berg, 2001). Two note takers who are post-graduate students of the University of Nigeria, Nsukka and natives of any of the communities used for the study were also recruited and trained on note taking just before the FGDs were conducted. The notes taken complement the audio-tape recordings. Each FGD lasted for a maximum of 90 minutes; with the team leader as the time keeper.

\section{Data Analysis}

All the FGDs were transcribed and translated verbatim from Pidgin English or Igbo language to English language with the help of note takers and two Igbo secondary school teachers who were also natives of the communities were the discussions took place. This enabled the researcher to ensure that no information was lost during the translation. It was also meant to validate views and as well make the data more reliable (Kalof, Dan, \& Dietz, 2008). Guided by the literature reviewed, analytical themes were developed from the transcripts on perceived challenges and coping strategies with health and psychosocial well-being of older cohorts including; views on changing traditional family structure, social support services, utilized health care service and perceived coping strategies. These views helped to portray the thoughts of the participants with verbatim quotes used in some instance. Quotations that are in line with the research questions were included within the text using an interpretative approach with FGD (01) representing views from caregivers and FGD (02) representing views from older cohorts. This is to allow our readers have a greater understanding of the persons or groups being described. This approach was considered suitable as it allows social action and human activities as quotes and text rather than figures.

\section{Results}

Relevant socio-demographic characteristics of the participants including age, educational attainment, monthly income, occupation, health status of older cohorts receiving care, old age benefits and utilized health care service were analyzed using percentages and are presented in Tables I and II respectively.

The data below represents the socio-demographic characteristics of the sampled caregivers in the selected three communities in Enugu-West zone. It can be depicted that consideration is given to gender equality in the Table I. 
Table I: Socio-demographic characteristic of FGD caregiver participants by sex Socio-demographic characteristics

\begin{tabular}{|l|c|c|c|}
\hline Age of participants & Male=20 & Female=20 & Total=40 \\
\hline $20-30$ years & $5(12.5 \%)$ & $14(35 \%)$ & $19(47.5 \%)$ \\
\hline $31-40$ years & $11(27.5 \%)$ & $3(7.5 \%)$ & $14(35 \%)$ \\
\hline $41-50$ years & $4(10 \%)$ & $3(7.5 \%)$ & $7(17.5 \%)$ \\
\hline Educational attainment & & & \\
\hline No formal education & $2(5 \%)$ & $3(7.5 \%)$ & $5(12.5 \%)$ \\
\hline Primary school (attended /completed) & $4(10 \%)$ & $2(5 \%)$ & $6(15 \%)$ \\
\hline Secondary school (attended /completed) & $13(32.5 \%)$ & $8(20 \%)$ & $21(52.5 \%)$ \\
\hline Tertiary school (attended /completed) & $1(2.5 \%)$ & $7(17.5 \%)$ & $8(20 \%)$ \\
\hline Occupation & & & \\
\hline Unemployed & $2(5 \%)$ & $3(7.5 \%)$ & $4(10 \%)$ \\
\hline Artisan & $6(15 \%)$ & $4(10 \%)$ & $10(25 \%)$ \\
\hline Business man/woman & $8(20 \%)$ & $6(15 \%)$ & $14(35 \%)$ \\
\hline Civil servant & $4(10 \%)$ & $7(17.5 \%)$ & $12(30 \%)$ \\
\hline Monthly income & & & \\
\hline $0-20,000$ naira & $4(10)$ & $12(30 \%)$ & $16(40 \%)$ \\
\hline $21,000-30,000$ naira & $2(5 \%)$ & $3(7.5 \%)$ & $5(12.5 \%)$ \\
\hline $31,000-40,000$ naira & $9(22.5 \%)$ & $3(7.5 \%)$ & $5(12.5 \%)$ \\
\hline $40,000-50,000$ naira & $3(7.5 \%)$ & $1(2.5 \%)$ & $4(10 \%)$ \\
\hline 50,000 and above & $2(5 \%)$ & $1(2.5 \%)$ & $3(7.5 \%)$ \\
\hline Health status of older cohorts & & & \\
\hline Physically fit & $8(20 \%)$ & $4(10 \%)$ & $12(30 \%)$ \\
\hline Has manageable illness & $3(7.5 \%)$ & $6(15 \%)$ & $9(22.5 \%)$ \\
\hline Has sense organ impairment & $7(17.5 \%)$ & $7(17.5 \%)$ & $14(35 \%)$ \\
\hline Has chronic illness & $2(5 \%)$ & $3(7.5 \%)$ & $5(12.5 \%)$ \\
\hline Utilized health care service & $8(20 \%)$ & $9(22.5 \%)$ & $17(42.5 \%)$ \\
\hline Hospitals & $3(7.5 \%)$ & $2(5 \%)$ & $5(12.5 \%)$ \\
\hline Drug dispenser (Chemist) & $5(12.5 \%)$ & $4(10 \%)$ & $9(22.5 \%)$ \\
\hline Traditional medicine & $4(10 \%)$ & $5(12.5 \%)$ & $9(22.5 \%)$ \\
\hline Local nurse & & & \\
\hline
\end{tabular}

Source: Field work survey 2019

The Table II below indicates socio-demographic characteristics of older cohorts who participated in the study. Equal number of male and female participants can be seen.

Table II: Socio-demographic of FGD older adult participants by sex

Socio-demographic characteristics

Sex of participants

\begin{tabular}{|l|c|c|c|}
\hline Age of participants & Male=8 & Female=8 & Total=16 \\
\hline $60-69$ years & $4(25 \%)$ & $4(25 \%)$ & $8(50 \%)$ \\
\hline $70-79$ years & $3(18.8 \%)$ & $3(18.8 \%)$ & $5(31.2 \%)$ \\
\hline 80 and older & $1(6.2 \%)$ & $1(6.2 \%)$ & $3(18.8 \%)$ \\
\hline Educational attainment & & & \\
\hline No formal education & $2(12.5 \%)$ & $1(6.2 \%)$ & $3(18.8 \%)$ \\
\hline Primary school (attended /completed) & $2(12.5 \%)$ & $2(12.5 \%)$ & $4(25 \%)$ \\
\hline Secondary school (attended /completed) & $3(18.8 \%)$ & $3(18.8 \%)$ & $6(37.5 \%)$ \\
\hline Tertiary school (attended /completed) & $1(16.2 \%)$ & $2(12.5 \%)$ & $3(18.8 \%)$ \\
\hline Old age benefits & & & \\
\hline Pension & $3(18.8 \%)$ & $2(12.5 \%)$ & $5(31.2 \%)$ \\
\hline Private investment & $2(12.5 \%)$ & $3(18.8 \%)$ & $5(31.2 \%)$ \\
\hline Assistance from children & $1(6.2 \%)$ & $2(12.5 \%)$ & $3(18.8 \%)$ \\
\hline Others & $2(12.5 \%)$ & $1(6.2 \%)$ & $3(18.8 \%)$ \\
\hline Health Status of older adult & & & \\
\hline Physically fit & $4(25 \%)$ & $3(18.8 \%)$ & $7(43.8 \%)$ \\
\hline Has minor illness & $2(12.5 \%)$ & $1(6.2 \%)$ & $3(18.8 \%)$ \\
\hline Has sense organ impairment & $2(12.5 \%)$ & $3(18.8 \%)$ & $5(31.2 \%)$ \\
\hline Has chronic illness & $0(0 \%)$ & $1(6.2 \%)$ & $1(6.2 \%)$ \\
\hline Utilized health care service & & & \\
\hline Hospitals & $2(12.5 \%)$ & $3(18.8 \%)$ & $5(31.2 \%)$ \\
\hline Drug dispenser (Chemist) & $2(12.5 \%)$ & $1(6.2 \%)$ & $3(18.8 \%)$ \\
\hline Traditional medicine & $3(18.8 \%)$ & $2(12.5 \%)$ & $5(31.5 \%)$ \\
\hline Local nurse & $1(6.2 \%)$ & $2(12.5 \%)$ & $3(18.8 \%)$ \\
\hline Source: Field work survey 2019 & & \\
\end{tabular}

Source: Field work survey 2019 
Table I summarizes the socio-demographic characteristics of the FGD (01) participants. The participants are all caregivers between the ages of 20 to 50 years. Close to half of the participants (47.5\%) were aged 20-30 years. Slightly above half $(52.5 \%)$ attended or completed secondary school education; the highest percentage of the participants (35\%) were business men and women while the highest percentage $(40 \%)$ earn 20,000 naira and below monthly. From the table also, it can be deduced that the highest percentage of older cohorts $(35.5 \%)$ experience sense organ impairment with $(42.5 \%)$ utilizing hospital health care service while a total of $(57.5 \%)$ preferred drug dispensers (chemist), traditional medicine and local nurse services respectively.

Table II shows the socio-demographic characteristics of older cohorts sampled. From the table, it can be deduced that half $(50 \%)$ of the participants were aged 60-69 years; while the highest percentage $(37.5 \%)$ have attended or completed secondary school education. It can be seen that there are equal percentage (31.2\%) in old age benefit from pension and private investment while less than half $(43.8 \%)$ claim to be physically fit with slightly equal percentages $(31.2 \%)$ and $(31.5 \%)$ utilizing hospital and traditional medicine health care services.

Perceived challenges and coping strategies in health and psychosocial wellbeing of older cohorts

In this theme, we present data that explain some perceived challenges and coping strategies that influence the health and psychosocial well-being of older cohorts. Both caregivers and older adults from the four rural communities selected for the study have something to share which we have categorized under the sub-theme below.

\section{Perceived challenges in health and psychosocial well-being of older cohorts}

In respect to this view, most of the participants agreed on the fact that longevity is achieved through adequate health management and psychosocial well-being of older adults by their caregivers. However, the participants highlighted the perceived challenges they encountered in health and psychosocial well-being of older cohorts.

\section{Changing traditional family structure}

Both male and female participants from the two groups agree on the fact that certain changes in traditional family system influence the coping strategy with health and psychosocial wellbeing. One of the male FGD (01) participants from Ngbogho-Agwu aged 28 years stated that:

Our society upholds the patriarchal family system and care giving is perceived as an obligation. This encourages care assistances to be completed by females more than males. In the contemporary society however, things have changed such that everyone (females) wants to go to school, get a job and live in the cities. This makes it difficult for older cohorts to be cared for in their homes.

Debating on the issue on contemporary family structure, one of the male FGD (02) participants from Abia-Udi aged 71 years had this to say:

Chie! [exclamation], times have changed that the young have no regards for the old. Families no longer travel to villages on festive periods; the traditional moon-light stories narrated by older cohorts is no more done; more so the previous Igbo [ethnic group] gerontological system where decisions are taken by the "Umunna', and 'Umuada' [old cohorts' kinsmen and women] are no longer cherished.

Two female FGD (01) participants from AkpugoOji aged 29 and 32 years respectively responded "most family caregivers experience difficulties in providing for their family needs, what more providing for the needs of their older cohorts..." another said "there is high demand for services in all sectors of life with little or no consideration given to the older cohorts but to immediate families' needs', 
In respect to the FGD (02) participants, they gave their views on changing traditional family structure. A female participant aged 69 years from Ngbogho-Agwu reported:

Providing care to older cohorts in our traditional society is perceived as the duty of the family members. However, older cohorts are left with various health challenges owing to the modern family structure and poverty. Poverty remains a major challenge in the changing traditional family structure. For instance, older cohorts are no longer productive from their retirement age of 60 years and above. As such they are forced to cope with the dwindling financial resources and high medical bills with little or no assistance from family members.... They may substitute to inadequate alternative medicine as their last resort to drugs.

Another 76 year old female participant from Oghe-Eziagu stated that the issue of rural-urban migration makes it difficult for older cohorts to cope with health and psychosocial well-being. For instance "I am a widow, living alone with all my children gone out for a better job. I feel bored and depressed with no one to talk to." Most of the participants supported the last speaker's view but have different opinions on the worst psychosocial challenge they encounter. In all these discussions with the two groups, the participants acknowledged that traditional family system is fading away and stressed on the hindrances that compounds this problem.

\section{Social support services}

Participants (male and female) in all FGD (01) sessions noted that social support services for older cohorts is essential to enable them cope with the health management and psychosocial wellbeing. According to a 45 year old female participant from Oghe-Eziagu, "provision of social support will help to alleviate the burden, stress and pains in care giving role...' In the FGD (01) session in Abia-Udi, a 35 year old female remarked that social support should be provided in the area of health assistance in coping with medical bills and providing alternative options in care giving. In her words she stated:

I believe it is the responsibility of older cohort's children to provide health care assistance to their parent. With the current situation in the country, assistance can also come from government, non-governmental organization (NGO) and renowned agency and institutions particularly in subsidizing medical bills for older cohorts. Health needs has always been a major challenge facing the aged, most often owing to inadequate financial conditions.

In the FGD (02) all male session, one of the participants in Akpugo-Oji has this to say:

I strongly acknowledged the fact that social support should be provided to assist older cohorts particularly those with chronic ill health. This support should focus on the health sector as it will not only relief the stress encountered by caregivers and families but will ensure quality well-being of the ageing population in the country.

The narratives collected from all the communities revealed a strong belief that social support if provided will be utilized by the caregivers and their older cohorts. Based on the response of the last speaker on providing support assistance in health care sector, we inquired from the participants their view on utilization of health care service.

\section{Utilization of health care service}

In respect to this view, both male and female caregivers and older adult participants in all the FGD sessions agreed that there are hospitals and health clinics provided by government and private individuals. However most of these health institutions are not utilized as a result of some reasons. One of the male participants in FGD (01) session from Abia-Udi asserted: 
There are good hospitals and clinics in our community. Some are suited far while some are quiet near. Most cases when you visit these health institutions, it becomes difficult to see a medical personnel based on the population already waiting. Also, cost of medical bill charged after treatment is too expensive for me to finance for my aged mother.

In addition to this view, two female participants from Ngbogho-Agwu and Oghe-Eziagu aged 42 and 46 years respectively chorused that "the attitude of the medical personnel is not encouraging and this makes it difficult to accompany older cohorts to pay regular hospital visitations and follow-up..." A male participant from Akpugo-Oji aged 37 years reported that his father simply resorts to alternative medicine as a result of the proximity and affordability.

In the FGD (02) male and female sessions, they are aware of the existence of the health care institutions. Most of them resort to alternative medicine with some reasons. One of the male participants from Abia-Udi aged 73 puts it:

Most times, I do not understand the drugs given to me by the medical personnel. In some drugs they will write $2 \times 3$ and in others it appears $1 \times 4$. I plead with them to tie the drugs according to the times I will take them. They do it but with grudges.

Another woman from Oghe-Eziagu aged 66 years acknowledged that "I do not like the sight of needles and syringes; this discourages me from English medicine'. In all these discussions from the two groups, the participants reported that they are aware of the existence of health care service in their locality but pointed out the challenges affecting utilization of health care service.

Determined coping strategies with health and psychosocial wellbeing

In the FGD (01) session, a male participant from Akpugo-Oji aged 46 years noted that "ageing is associated with decline in body functioning, it then becomes essential that strategies should be adopted to assist older cohorts". One of the female participants in Abia-Udi narrated:

After retirement, my aged mother developed chronic illness and have been bed ridden for close to three years now. It has not been easy for me. I had to change her bed linen, sleeping position, provide feeding assistance and toileting. In fact, there are occasions when I will have to spend the whole day providing care assistance. In such situations I can't help but sing religious songs to cope with the situation.

Another male participant from Oghe-Eziagu aged 35 years who was very vocal in the group said that "I have been living with my father for some months now, at weekends we go for a long walk, this aids his mobility with the walking support provided for him'. One of the participants from Akpugo-Oji aged 42 years said that he bought hearing aid and a pair of reading glasses for his aged mother to assist her declining sense organs, but she continued complaining in spite of this effort.

In the all men FGD (02) session, a participant from Ngbogho-Agwu aged 67 years noted that "when I am alone and depressed, I tune on my television or radio set and listen to comedy talks/shows and laugh out my sorrows and worries..." A female participant from Akugo-Oji aged 61 years asserted:

I live in my personal home at Oji, my saving grace is that I try and maintain good communication network with family and friends to prevent being depressed or bored. Thanks to cell phone, I call my children often and they also call me regularly. I also tend to forget what they tell me easily so I have a dairy where I write important information I would have forgotten ordinarily... 
Majority of the participants from the two groups all noted different coping strategies. This indicates that they have knowledge of some minor coping strategies with health and psychosocial wellbeing, though this knowledge is not adequately put into practice.

\section{Discussions}

The perceived challenges and strategies in coping with health and psychosocial wellbeing of older cohorts in four rural communities in Enugu-West Senatorial zone was accessed in this article. A unique finding in this study that is not common in other reviewed literature is the role of medical social workers in providing health care assistance. The study participants neither understand the roles of social workers nor know their mission in the health care setting; as such no participant was able to mention or highlight some of the roles of social workers in homes or medical institutions. This finding corresponds to the view of Okafor et al (2017) which states that in Nigeria, the practice of social work profession in health care setting is not yet popular and encounters uncertain future particularly in rural communities. Generally, participants from the two groups have appreciable knowledge that aging is associated with ill health. This was stated by one of the caregiver participants in Apkugo-Oji who noted that "ageing is associated with decline in body functioning". This view is in accordance with WHO (2015) report which states that with changing body composition associated to ageing, older cohorts becomes functionally disabled and will require some form of assistance. Our data in Tables I and II indicates that a good number of the caregivers' older cohorts $(70 \%)$ and more than half $(56.2 \%)$ of the sampled older cohorts were not physically fit with many of them suffering from sense organ impairment. This finding is in line with the report by National Ageing Research Institute (2014) and Abanyam (2013) that as people grow older, they face different health experiences and conditions and are prone to diseases and sickness.
Results from our findings indicated that majority of the participants $(80 \%)$ and $(81.3 \%)$ attended or completed secondary school. Also, response from the two categories of FGD participants shows that minor techniques including singing, use of mass media and communication among others were adopted to relieve burden, depression and ensure coping strategy. These findings are associated to the fact that variable like educational attainment of the participants may partially influence their knowledge needed to fully practice the major coping strategies. They are also in line with the view of Braham et al (2018) which maintains the crucial need to offer skill training program and self empowerment strategies that would address specific health and psychosocial challenges and as well provide the needed knowledge in psychological and social skills in coping with changing needs of older cohorts. These points to the need for a deliberate programme to educate older cohorts, family members and particularly caregivers on ways to cope with the health and psychosocial well-being of their aged care recipient that is within their economic and physical strength.

Scholars believe that changing traditional family structure is an impediment to coping with health and psychosocial wellbeing of older adults (Abanyam, 2013; Akeleke et al, 2017; Alwajudadewusi, 2019 \& Okoye, 2014). Data gathered in this present study confirm this belief. From a female FGD (01) participant aged 38 years, she noted that "our society upholds the patriarchal family system and this encourages domestic chores to be completed by females more than males...'. Also the FGD (02) female participant aged 69 years from Ngbogho-Agwu responded that:

Providing care to older cohorts in our traditional society is perceived as the duty of the family members. However, older cohorts are left with various health challenges owing to modern family structure and poverty. Poverty remains a major challenge in the changing traditional family structure. For instance, older cohorts are no longer 
productive from their retirement age of 60 years and above. As such they are faced to cope with their dwindling financial resources and high medical demand with little or no assistance from family members... They may substitute inadequate alternative medicine as their last resort to drug.

The views of these participants holds that changing family structure owing to the modern (nuclear) family system and economic situation, is an influencing factor to coping with their health and psychosocial well-being. This finding also can be associated to the theory of planned behavior which states that when cultural values no longer promote good health, they lead to behaviours that run into conflict with established health standards (Agbawodikeizu et al 2019). Stretching this debate, one of the FGD (02) participants reported that "poverty remains a major challenge, as such most family caregivers experience difficulties in providing for their family needs and abandoning the needs of their older parents". This is reflected in Table I where less than half $(40 \%)$ of the caregivers earn below 20,000 thousand naira while in Table II less than a quarter $(18.8 \%)$ of older cohorts receives assistance from their children. In view of this finding, it becomes imperative that financial assistance through health care incentives including free primary health care and health education program will ensure healthy ageing and psychological well-being of older cohorts.

Data from this study suggests that social support service is highly welcomed by the two groups. Participants suggests that social support should be provided in the areas of health assistance particularly in coping with health, medical bills and providing alternative options in care giving. These major challenges of older cohorts, family members and caregivers can be alleviated by government, non-governmental organizations (NGOs) and renowned institutions and agencies. This finding is in line with the view of Oluwagbemiga (2016) which states that the absence of quality formal support for older adults increases vulnerability particularly with ill-health. The present study also found that older cohorts do not adequately utilize the health care system. This is based on the data in Table I which indicates that slightly below one-quarter $(22.5 \%)$ of the participants preferred alternative medicine. Similarly, in Table II, more than one-quarter $(31.2 \%)$ preferred alternative medicine which is equivalent to the percentage that preferred English medicine. More so, in all the FGD sessions, the participants did not respond to early hospital visitation in coping with health and psychological well-being. These evidences are clear indications that older cohorts may not adequately utilize health care services but may resort to the use of inadequate alternative medicine which they perceive to be cheaper and accessible (Ene, 2018; Schnabel, Binting, Witt \& Teut, 2014).

Following all these perceived challenges and strategies in coping with health and psychosocial well-being of older cohorts by their caregivers; implication for medical social work profession in Nigeria still abound. It is commendable to note that when a person sets out to help others especially those most vulnerable (older cohorts), the worker assumes a serious responsibility. Social work as an action oriented profession promotes social change, cohesion, empowerment and liberation of the people (Okoye et al, 2017). They constitute an important part of health, psychological and social well-being by providing essential interventive roles, skills, and strategies to older cohorts, family members and caregivers particularly in rural communities. This will not only help in the promotion of rural medical social work practice but in coping with the health and psychosocial well-being of the ageing population in Nigeria.

While this present study has contributed to literature on coping with health and psychosocial well-being of older cohorts in Nigeria, certain limitations in the study need to be pointed out. This study based its analysis on data obtained from purposively selected three rural communities' older cohorts and caregivers. 
Perhaps, a more representative sample that will ensure data from different urban/rural communities may allow for bigger and better picture of coping with health and psychosocial well-begin in Nigeria.

\section{Acknowledgement}

The research received no specific grant from any funding agency in the public, commercial or notfor-profit sectors.

\section{Conflict of interest}

The authors declare that there is no conflict of interest to this paper.

\section{Copyright license}

This manuscript has been read and approved by all the authors. They have granted copyright license to Francis and Taylor publishers. No portion of this paper has in any way been published elsewhere and it has not been submitted simultaneously for publication elsewhere.

\section{Reference}

1. Abanyam, N.L, (2011). The problem of the aged in Nigeria. Journal of Research and Contemporary Issues, 6 (1\&2).

Retrieved from https://www.researchgate.net.3309...

2. Abanyam, N., L.(2013). The changing privileges and challenges of older people in contemporary African society. Global Journal of Art, Humanities and Social Sciences, 1(4), 34-44. Retrieved from http://www.ea.journals.org

3. Adebanjo, K. (2019, January 30). Older person's day: Eight months after law passage, Nigerians senior citizens still out of sight. Premium Times Newspaper, pg.5.

4. Adebowale, S. (2016). Nigeria's population elderly to constitute $20 \%$ in 2016. Retrieved from https://the eagle.online.com.ng > Nigeria

5. Adebowale, S.A, Attle, O.\& Ayeni O. (2012). Elderly well- being in a rural community in North- Central Nigeria, subSaharan African. Public Health Research, 2(4), 92-101.

DOI:10.5923.j.phr.201202040.05.

6. Adeleke, R.O., Adebowale, T.O, Oyinlola, O.I (2017). Profile of elderly patients presented with psychosocial problems in Ibadan. M.O.J Gerontology \& Geriatric, 1(1), 26-36.

7. Adinma, E. D., Brian, D.J. \& Adinma, I. (2010). Community based health care financing: An untapped option to a more effective health care funding in Nigeria. Nigerian Medical Journals, 2(1), 21-31.

8. Agbawodikeizu, U., Agwu, P., Okoye, U. \& Igwe, I. (2019). Controversies in preparing for end-of-life in Nsukka town, Nigeria and suggestions for Nigerian based social work practice. Journal of Social Work \& Social Sciences, 20 (2), 47-64.

9. Ajzen, I. (1985). From intentions to actions: A theory of planned behavior. In J. Kuhl \& J. Beckman (Eds.), Actioncontrol: From cognition to behavior (pp. 11-39). Heidelberg: Springer

10. Alawajud-adewusi, M.B (2019). Psychosocial problems of elderly persons in Lagos State, Nigeria. Implication for counseling practice. Retrieved from https://www.researchgate.net/profile/Alwa jud-adewusi-mirian-

Bukola/publication332652987.

11. Alenoghena, I., Aigbirenolen, A.O, Abjegali, C. \& Ejiemai, E. (2017). Primary health care in Nigeria: Strategies and constrains in implementation. Retrieved from

https://www.researchgate.net>publication.

12. Akpunne, B.C. (2015).Psychosocial factors and psychological wellbeing of formal caregivers. European Journal of Humanities and Social Sciences, 34(1), 98112.

13. Animasahun, V.J. \& Chapman, H.J. (2017). Psycho-social health challenges of 
the Elderly in Nigeria: A narrative review. African Health Sciences, Makerere Medical School Journal, 1(1), 17-23.

14. Ayangunna, J. A. \& Mojoyiola, J. K. (2012). Social Work and Welfare of the Aged in Nigeria. In H., O. Osinowo, O. A. Moronkola, D.A.Egunyomi, D. A. (Eds.). The adults and aged in Nigeria: Issues and researches (pp17-30). Ibadan: Royal people Nig. Ltd.

15. Barham, E.J, DelPrette, Z.A \& Queluz, F.N. (2018). The relationship between social skills and psychosocial adjustment among those who care for older adults. Retrieved from https://doi.org/10.1590/1982-4327e2917.

16. Berg, B. L. (2001). Qualitative research method for the social sciences. United State of America: Allyn and Bacon publishers.

17. Correa-Torres, S. M., Conroy, P., RundleKahn, A., \& Ogilvie T (2018). Experience of students who are visually impaired receiving services by Disabilities Support Services (DSS) office in higher education institutions. Journal of Blindness, Innovation and Research, 8(2), 122-131.

18. Dokpesi, A.O. (2017). Senior citizens health insurance programme (SCHIP): a policy framework for healthy ageing in Nigeria. Ageing International Journal,42, 290-305.DOI:10.1007/s12126-017-9299-7

19. Ene, J.C. (2010). Adult Off-springs' Perception of their Care Giving Role towards Elderly Parents: A Case Study of Nsukka L.G.A of Enugu State. (Master's thesis, University of Nigeria, Nsukka, Nigeria).

20. Ene, J.C, Nnama-Okechukwu, C., Uzuegbu, C. \& Okoye, U. (2018). Social work with family. In U.O, Okoye, N. Chukwu \& P. Agwu (Eds.). Social work in Nigeria: Book of Readings (Chapter 16, pp198-211). Nsukka, Enugu state: University of Nigeria Press.
21. Ene, J., Adewoyin, Y., Chukwu, A. \& Patrison, T. (2018). Determinants of primary health care utilization by older adults and the implication for social work practice in Enugu State, Nigeria. Proceedings of the $1^{\text {st }}$ International conference of the Department of Social Work, University of Nigeria, Nsukka.

22. Friedemann, M.,L. \& Buckwalter, K., C. (2014). Family caregivers' role and burden related to gender and family relationship. Journal of the American Geriatric Society, 58(1) 937-943.

23. Irish Association of Social Work (IASW, 2011). The Role of the Social Worker with older adult persons. Prepared by: The Irish Association of Social Workers (IASW). Special Internet Group Ageing (SIGA) p7.

24. Kalof, L., Dan, A., \& Dietz, T. (2008). Essential of social research. New York: Open University Press.

25. Litwin, H., Stoeckel, K.J \& Roll, A (2014). Relationship status and depressive systems among older co-resident caregivers. Ageing and mental health, 18(1), 225-231. DOI: 10.1080113607863.2013.837148

26. National Ageing Research Institute (NARI, 2014). Healthy ageing. Retrieved from https://www.who.int.ageing.

27. National Bureau of Statistics (2017). Demographic Statistics Bulletin 2018. Retrieved from https://nigerianstat.gov.ng.demographicstat isticbullentin

28. Moody, H.R (2010). Ageing: Concepts and controversies ( $6^{\text {th }}$ Ed.). U.S.A: Pine Forge Press

29. Okafor, A.E, Onalu, C., Ene, J.C \& Okoye, U.O (2017). Social work in health care setting.

30. In U.O, Okoye, N. Chukwu \& P. Agwu (Eds.). Social work in Nigeria: Book of readings (Chapter 12, pp172-183). 
Nsukka, Enugu state: University of Nigeria Press.

31. Okoye, U.O. (2014). Financial incentive to support family caregivers of older adults in Nigeria: A policy consideration. Research on Humanities and Social Sciences 4(4) 15-22. Retrieved from https://pdfs.semanticschloar.org/.../12fef06 cfca21eb10cdf2482a5706fe7aa4.pdf

32. Okoye, U., O. \& Asa, S., S. (2011). Care giving and stress: Experience of people taking care of elderly relations in SouthEastern Nigeria. Arts and Social Science Journal, 29(2),12-20. Retrieved from https://astonjournals.com/manuscripts/vol2 011/ASSJ-29- vol2011.pdf.

33. Okoye, U.O., Ebimgbo, S., \& Ene, J. (2017). Social work with older adults. In Okoye, U., Chukwu, N., Agwu, P. (Eds.). Social Work in Nigeria: Book of Readings (Chapter 14, pp172-183). Nsukka, Enugu state: University of Nigeria Press Limited,

34. Oluwagbemiga, O. (2014). Effect of social support system on the psychosocial wellbeing of the elderly in old people's home in Ibadan. Journal of Gerontology \& Geriatric Research, 5(5), 343-352. Doi:104172/2167-7182.1000343.

35. Penning, M.J., Zheng Wu, L. (2016). Caregiver stress and mental health: Impact of care giving relationship and gender. The Gerontologist $56 \quad$ (6), 1102-1113. Retrieved from https://doi.org110.1093/geront/gny038

36. Portray, J.A (2016). Importance of medical social workers. Retrieved from www.ajmc.com-julie-potyraj-2016/03.

37. Schnabel, K., Binting, S., Witt, C., Teut, M. (2014). Use of complementary and alternative medicine by older adults- a cross sectional survey. BMC geriatric Journal, 14(38), 45-49.
38. United Nations Department of Economics and Social Affairs, Population Division (UNDESA, 2012). World Population prospects: The 2010 revision. Retrieved from http://www.un.org/esa/population /2012WorldPopAgeingDev Chart/2012 PopAgeing and Dev-WallChart.pdf.

39. United States Census Bureau Statistic (2016). An Ageing World: 2015. International Population Reports. FIAP. Boletin-0tras publications.

40. Usman, A. (2018, May 8). Nigeria has only 7 geriatrics to carter for over $9 \mathrm{~m}$ aged persons. News Agency of Nigeria. Retrieved from http://www.pluse.ng>local>nig

41. World Health Organization (WHO, 2010). Health system financing: The part to universal coverage. World Health Report. WHO Publications.

42. World Health Organization (2014). Global Health Expenditure: Nigeria Health Expenditure. .Index Mundi. Retrieved from htttp://www.who.int/nha/database.

43. World Health Organization (WHO, 2017). World health report executive summary achieving health for all. Retrieved from https://www.who.int/whr/1998/media.cent er/executivesummary6/en.

44. Wrigon, C. (2018, August 8). Nigerian government partners with the World Health Organization to improve healthy ageing. World Health Report. Retrieved from https://www.afro.who.int/news/nig. 